orang-utan and gibbons. No laboratory man could have shown the insight he reveals in his last paragraph, where he points out that our giant urban agglomerations, far from being an unnatural environment for man, are at last the means of freeing him from the small-community restrictions imposed on him by thousands of years of agriculture and returning him to the hunter-gatherer environment in which he evolved. His chapter on conservation also contains many valuable suggestions, especially for enabling zoos, research institutes and other 'consumers' of wild apes to stop their fatal drain on the rapidly diminishing wild stocks.

The Napiers have provided an essential reference book for all who are studying or are in any way interested in the primates as a whole, including the disputed tree-shrews. Besides much general information on the traditional aspects of their biology, there is a summary of the characteristics of each genus, with supplementary taxonomic notes, a complete check-list, special data on macaques, which are the most researched-on primates, and a final section containing useful statistics on such aspects as gestation periods, chromosome numbers, longevity records and comparative weights and dimensions. Their one weakness lies where Vernon Reynolds is so strong, in summarising the enormous amount of new data produced by the present generation of young ethologists who have actually gone out and lived with primates in the wild.

RICHARD FITTER

\title{
Lemur Behaviour: A Madagascar Field Study by Alison Jolly. University of Chicago Press, 52s.
}

In the last ten years an increasing number of people interested in primate behaviour have moved from the laboratory to the field. More often than not, this entirely welcome development has been motivated by a desire to explain the evolution of human social organisation rather than by curiosity or the pleasures of field work. Alison Jolly shares the ambition to explain away; but this has not prevented her from describing with care and sensitivity the ecology and social behaviour of two species of prosimian, Propithecus verreauxi and Lemur catta. For anyone interested in the evolution of primate behaviour, the lemurs must have seemed promising material since in many ways they appeared primitive. Certainly they are peculiar - which is not perhaps surprising as they have supposedly been isolated on Madagascar for 50 million years. Mrs Jolly found, for example, that the breeding season of Lemur catta is highly restricted and synchronised - which incidentally puts another nail in the coffin of the idea that sex alone keeps primate societies together.

The lemurs' sense of smell is extremely well developed and they produce a number of secretions which seem to be used in social displays. Mrs Jolly became aware of her own limitations while watching what she calls 'scent fights'; in this respect the lemur-watcher is more handicapped than, say, the bird-watcher. Nevertheless there was plenty for Mrs Jolly to look at. The territorial behaviour of Propithecus verreauxi is striking and also a little absurd. One band will defend an area from another band but in doing so will always face away from the centre of their territory. As a result in border skirmishes, rival bands may end up with their backs to each other.

This attractive if somewhat specialised book is marred by an attempt to interpret the observations in terms of recently fashionable ideas which, to my mind, are ill-defined or tautologous. The problems which Mrs Jolly set out to tackle remain elusive, and theorising about the evolution of human behaviour seems emptier than ever. It seems so, however, as a result of the recent field work of which this study is an excellent part.

P. P. G. BATESON 